\title{
PROSPECÇÃO CLONAL E OCORRÊNCIA DE VIROSES DA CULTIVAR FOLHA DE FIGO NA REGIÃO DE CALDAS, MG
}

\section{CLONAL PROSPECTION AND VIRUSES OCCURRENCE IN THE GRAPEVINE CV. 'FOLHA DE FIGO', AT CALDAS, MG, BRAZIL}

\author{
Fabíola VILLA ${ }^{1}$ \\ Murillo de Albuquerque REGINA ${ }^{2}$ \\ Ângelo Albérico ALVARENGA ${ }^{3}$ \\ Moacir PASQUAL ${ }^{4}$ \\ Regiane Abjaud STOPA ${ }^{5}$
}

\section{RESUMO}

A produtividade da videira (Vitis labrusca L.) cultivar Folha de Figo na região de Caldas, MG, é muito baixa, devido, entre outros fatores, à ocorrência de viroses. Objetivou-se neste estudo, selecionar clones mais produtivos dessa cultivar, bem como a sanidade dos mesmos. O trabalho iniciou-se em 1994, em vinhedo da EPAMIG e propriedades particulares, onde procedeu-se a uma primeira seleção de 137 plantas, obedecendo a critérios visuais de vegetação, produção e identidade varietal. Estas foram marcadas para o acompanhamento do volume e qualidade da produção. Durante a primavera de 1996, antes da colheita, por ocasião do início da maturação dos cachos, iniciaram-se os trabalhos de seleção massal e definiram-se como parâmetros dessa seleção a produção por planta e o índice de fertilidade. O teste DAS-ELISA foi realizado para verificar o estado sanitário dos 19 clones através da detecção dos seis principais vírus que ocorrem em videira. Foram detectados apenas o vírus da canelura do tronco da videira (GVA) e o vírus associado ao enrolamento da folha da videira (GLRaV-3) em $31,58 \%$ e $15,79 \%$ das plantas testadas, respectivamente. Contudo, todas as plantas infectadas apresentaram produções médias superiores a $5,0 \mathrm{~kg}$ planta $^{-1}\left(13,29 \mathrm{tha}^{-1}\right)$, comprovando que a infecção por estes vírus não afetaram a produtividade destas videiras.

Palavras-chave: Vitis labrusca; seleção clonal; teste ELISA.

\begin{abstract}
The productivity of grapevine (Vitis labrusca L.) cv. Folha de Figo in the region of Caldas, Minas Gerais state, Brazil, is very low, due to, among others factors, the occurrence of viruses. In this study we selected and evaluated the genetic similarity of this cultivar and surveyed possible viruses present in these plants. This work started in 1994 at EPAMIG's vineyard and private orchards, where a first selection was proceeded from 137 plants, obeying the vegetation visual criteria, production and varietal identity. These had been marked for the accompaniment of the volume and quality of the production. During the spring of 1996, before the harvest, during the beginning of the maturation of the clusters, it was initiated the works of massal selection and defined as parameter of this selection the production for plant and the fertility index. The DAS-ELISA test was carried out to verify the detect possible viruses in 19 selected clones. There were detected only the Grapevine virus $A$ (GVA) and Grapevine leafroll associated virus 3 (GLRaV-3) in $16 \%$ and $47 \%$ of the tested plants, respectively. The infected plants, however, presented the average productions better than $5.0 \mathrm{~kg} \mathrm{plant}^{-1}\left(13,29 \mathrm{t} \mathrm{ha}^{-1}\right)$, revealing that these viruses had little effect on the yield.
\end{abstract}

Key-words: Vitis labrusca; clonal selection; ELISA test.

\footnotetext{
${ }^{1}$ DSc., Pós-Doutoranda em Fitotecnia, Empresa de Pesquisa Agropecuária de Minas Gerais (EPAMIG), Bairro Vargedo, Maria da Fé, Minas Gerais, Brasil. CEP: 37517-000, E-mail: fvilla2003@libero.it Autor para correspondência

${ }^{2}$ DSc., Pesquisador Empresa de Pesquisa Agropecuária de Minas Gerais (EPAMIG) / Fazenda Experimental Caldas (FECD), C.P. 33, CEP: 37780-000, Caldas, Minas Gerais, Brasil. E-mail: murillo@epamigcaldas@gov.br

${ }^{3}$ DSc., Pesquisador Empresa de Pesquisa Agropecuária de Minas Gerais (EPAMIG) / Centro Tecnológico do Sul de Minas (CTSM), CEP: 37200-000, Lavras, Minas Gerais, Brasil. E-mail: angelo@epamig.br

${ }^{4}$ DSc., Professor Adjunto do Dep. de Agricultura, Universidade Federal de Lavras (UFLA), C.P. 37, CEP: 37200-000, Lavras, Minas Gerais Brasil. E-mail: mpasqual@ufla.br

${ }^{5}$ Mestre em Genética e Melhoramento Vegetal, Departamento de Biologia, Universidade Federal de Lavras (UFLA), Lavras, Minas Gerais, Brasil. E-mail: regianefloresta@hotmail.com
} 
VILLA, L. et al. Prospecção clonal e ocorrência de viroses...

\section{INTRODUÇÃO}

A região de Caldas, situada no Sul de Minas Gerais, já foi considerada como importante ponto de referência para o país na produção de uvas e vinhos, por volta das décadas de 40 a 60 . No entanto, o envelhecimento dos parreirais e elevados índices de pragas e doenças causaram desestímulo aos produtores, culminando com grande queda na produção de uvas (Gonçalves, 1996).

As viroses representam um dos mais importantes problemas fitossanitários da viticultura mundial, ocorrendo em praticamente todas as regiões onde a videira (Vitis spp.) é cultivada. De modo geral, essas doenças caracterizam-se por induzir lenta e gradual degenerescência da planta, causando constantes perdas na produção de uva, que chegam a perdas totais em variedades mais sensíveis (Amorim \& Kuniyuki, 1997). As viroses interferem, de uma maneira geral, nos processos fisiológicos da planta, causando prejuízos tais como: diminuição no número e tamanho de cachos, maturação irregular e queda no teor de açúcar da uva (Kuhn et al., 1996).

Segundo Martelli (2006), os vírus considerados mais importantes e mais difundidos da videira são: vírus da canelura do tronco da videira (Grapevine virus A - GVA), vírus do fendilhamento cortical da videira (Grapevine virus B - GVB), vírus do enrolamento das folhas da videira (Grapevine leafroll virus - GFRV), vírus do mosaico do Traviú (Grapevine fanleaf virus - GFLV) e vírus associado ao enrolamento da folha da videira (Grapevine leafroll associated virus - GLRaV-1 e 3). Para se confirmar a presença de vírus em vegetais, recorre-se a testes de diagnose, tais como: sorologia (ELISA), microscopia eletrônica, técnicas moleculares e plantas indicadoras (Kuniyuki et al., 2002).

Devido a importância econômica da cultivar Folha de Figo para a viticultura brasileira e mineira, o produtor da região insiste em mantê-la, fato que aponta para a necessidade de se restaurar as suas características originais. Neste contexto, esse trabalho teve como objetivo iniciar um programa de seleção clonal para a cv. Folha de Figo, de forma a resgatar possíveis mutações de interesse agronômico e de sanidade comprovada e ao mesmo tempo avaliar quais os vírus que estavam presentes nestas plantas.

\section{MATERIAL E MÉTODOS \\ Local do trabalho e seleção das plantas \\ O presente trabalho iniciou-se em 1994, por meio da seleção massal e do acompanhamento da produção de um grupo de plantas da cultivar Folha de Figo em vinhedos instalados no município de Caldas, MG, situado a $1.150 \mathrm{~m}$ de altitude, $21^{\circ} 40^{\prime}$ de latitude $S$ e $40^{\circ}$ de longitude $W$. O clima apresenta temperatura média anual de $19^{\circ} \mathrm{C}$, com médias das mínimas de $13^{\circ} \mathrm{C}$ e das máximas de 26 ${ }^{\circ} \mathrm{C}$, umidade relativa de $75 \%$ e precipitação pluviométrica total de $1.500 \mathrm{~mm}$ anuais.}

Esta seleção foi realizada visualmente por meio do vigor e produção de plantas, com as características de identificação varietal (forma e coloração das folhas, ramos e cachos) e sem sintomas de viroses. Inicialmente, foram selecionadas 27 plantas em vinhedo da EPAMIG, nas quais se procedeu o acompanhamento da produção durante quatro anos. Durante a colheita foi feita a pesagem da produção ( $\mathrm{kg}$ planta $\left.{ }^{-1}\right)$, medição do teor de açúcares ( ${ }^{\circ}$ Brix), da acidez total $\left(\mathrm{cmol}_{\mathrm{c}} \mathrm{dm}^{-3}\right)$, do $\mathrm{pH}$ e avaliação do índice de fertilidade dos ramos de cada planta, calculado pela fórmula:

Índice de fertilidade de gemas/planta = número de cachos/ramos

Ao mesmo tempo, durante a primavera de 1996, por ocasião do início da maturação dos cachos, iniciaram-se os trabalhos de seleção massal com outros viticultores do município de Caldas, MG. Foram escolhidos 17 viticultores distribuídos nas diferentes regiões vitícolas do município, procurando identificar diferentes condições ecológicas (tipo de solo, exposição, vegetação adjacente) de forma a aumentar as possibilidades de identificação de clones mutantes superiores. Percorreram-se os vinhedos selecionando-se visualmente as plantas mais produtivas e com identidade varietal indiscutível. Foram escolhidos somente vinhedos de pé-franco e com idade superior a 20 anos, de forma a reduzir os riscos de infecção pela enxertia.

A partir da primeira seleção massal, definiram-se como parâmetros de seleção a produção por planta e o índice de fertilidade, estabelecendo arbitrariamente a produção mínima de 5,0 kg planta ${ }^{-1}$ e/ou índice de fertilidade dos ramos próximo ou superior a 1,0. Foi mantida uma planta "candidata a clone" com produção e índice de fertilidade inferiores no "stand" como testemunha local.

Os clones inicialmente selecionados durante a fase de prospecção foram multiplicados por meio de estaquia em vasos e mantidos em casa de vegetação (5 repetições planta ${ }^{-1}$ ) adubados por fertirrigação.

\section{Teste DAS-ELISA}

O teste sorológico foi realizado no Laboratório de Virologia da EMBRAPA/Centro Nacional de Pesquisa Uva e Vinho (CNPUV), localizado em Bento Gonçalves, RS. Para a realização deste teste foram empregados antissoros da Agritest, da Itália e seguidas as recomendações dos fornecedores (antissoros monoclonais: vírus da canelura do tronco da videira (Grapevine virus A GVA), vírus do fendilhamento cortical da videira (Grapevine virus B - GVB) e vírus do enrolamento das folhas da videira (Grapevine leafroll virus GFRV) e policlonais: vírus do mosaico do Traviú (Grapevine fanleaf virus - GFLV) e vírus associado ao enrolamento da folha da videira (Grapevine leafroll associated virus - GLRaV-1 e -3).

Para a detecção desses vírus foram coletadas 10 folhas por planta. Para a detecção do vírus GFRV e do GFLV, coletaram-se folhas jovens, 
VILLA, L. et al. Prospecção clonal e ocorrência de viroses...

próximas a região do ápice dos ramos durante a primavera. Para a detecção do GVA, GVB, GLRaV1 e GLRaV-3, foram amostradas folhas adultas, situadas na base dos ramos e durante o final do ciclo vegetativo. As folhas amostradas foram imediatamente acondicionadas em sacos plásticos e enviadas para o Laboratório.

O teste utilizado foi o DAS-ELISA, o extrato foliar diluído $1: 5(\mathrm{~m} / \mathrm{v})+5 \mathrm{~cm}^{3}$ de tampão de extração (Fajardo et al., 2000). O controle negativo foi constituído pelo extrato foliar da videira (cv. Folha de Figo) livre de vírus e o positivo foi obtido de preparações parcialmente purificadas de cada vírus. O valor de absorbância (leitura), no mínimo, superior a duas vezes o valor verificado para o controle negativo foi considerado positivo.

As placas foram cobertas com solução de $200 \mathrm{~mm}^{3}$ de lgG (Imunoglobulina $\mathrm{G}$ ) na detecção de cada vírus (GLRV, GFLV, GVA, GVB, GLRaV-1 e GLRaV-3), diluída em tampão de revestimento ou de cobertura (carbonato de sódio $0,05 \mathrm{~mol} \mathrm{dm}^{-3}, \mathrm{pH}$ 9,6 ), incubadas a $37^{\circ} \mathrm{C}$, por $4 \mathrm{~h}$ e lavadas três vezes com PBS, pH 7,4 e Tween 20 (detergente) a $0,05 \%$ (v/v) (PBS-T - tampão de lavagem). Em seguida, foram adicionados $200 \mathrm{~mm}^{3}$ de extrato foliar diluído 1:5 em tampão tris- $\mathrm{HCl}$ (antioxidante) $0,5 \mathrm{~mol} \mathrm{dm}^{-3}, \mathrm{pH} 8,2, \mathrm{NaCl}$ a $0,8 \%(\mathrm{~m} / \mathrm{v})$, PVP (polivinilpirrolidona) a 2\% (m/v), PEG 6000 (antioxidante) a $1 \%(\mathrm{~m} / \mathrm{v})$ e Tween 20 a $0,05 \%(\mathrm{v} / \mathrm{v})$. As placas foram incubadas a $4{ }^{\circ} \mathrm{C}$ por $14 \mathrm{~h}$ e lavadas com PBS-T, seguindo-se adição de 150 $\mathrm{mm}^{3}$ do conjugado diluído em tampão PBS-T com
PVP a $2 \%(\mathrm{~m} / \mathrm{v})$ e albumina de ovo a $0,2 \%(\mathrm{~m} / \mathrm{v})$. Após incubação por $4 \mathrm{~h}$, procedeu-se a nova lavagem e adicionou-se o substrato da enzima em dietanolamina a 10\% (v/v), pH 9,8 (Clark \& Adams, 1977; citado por Fajardo et al., 2000). As leituras das placas foram realizadas a cada meia hora, a $405 \mathrm{~nm}$ em espectofotômetro para placa ELISA Labsystems Multiskan MS.

\section{RESULTADOS E DISCUSSÂO}

\section{Prospecção clonal}

Vinhedo da EPAMIG

Dentre as 27 plantas inicialmente amostradas foram selecionadas 12 que apresentavam produção média próxima a $5,0 \mathrm{~kg}$ planta $^{-1}$. Pelos dados da Tabela 1 pode-se verificar que a produção média de quatro anos oscilou entre 4,8 e $10,4 \mathrm{~kg} \mathrm{planta}^{-1}$. Estes valores levam a uma produção média por hectare situada entre 12,796 e $27,726 \mathrm{~kg}$, considerando-se a densidade usual de 2.666 plantas $\mathrm{ha}^{-1}$, produtividade superior àquela avaliada na região de Caldas por Regina et al. (1998). Posteriormente, Souza et al. (2002), estudando um grupo de plantas jovens de 'Folha de Figo' na EPAMIG de Caldas, MG, obtiveram uma produção de $3,6 \mathrm{~kg}$ planta ${ }^{-1}$, valor abaixo do observado neste estudo. Também se observou grande variabilidade de potencial produtivo entre plantas dentro de um mesmo vinhedo, corroborando a importância da seleção clonal para o aumento da produtividade.

TABELA 1 - Produção (kg planta-1 ${ }^{-1}$ dos diferentes clones da cultivar Folha de Figo (Vitis labrusca L.) durante quatro anos de observação na EPAMIG, Caldas, MG.

\begin{tabular}{cccccc}
\hline Clone & 1994 & 1995 & 1996 & 1997 & Média \\
\hline $1 \mathrm{E}$ & 9,3 & 1,4 & 4,1 & 4,3 & 4,8 \\
$2 \mathrm{E}$ & 9,0 & 4,1 & 8,1 & 8,3 & 7,4 \\
$3 \mathrm{E}$ & 6,7 & 5,7 & 6,1 & 8,7 & 6,8 \\
$4 \mathrm{E}$ & 8,5 & 5,0 & 6,3 & 10,8 & 7,6 \\
$5 \mathrm{E}$ & 9,5 & 3,5 & 2,9 & 6,5 & 5,6 \\
$6 \mathrm{E}$ & 6,6 & 5,2 & 6,9 & 9,8 & 7,1 \\
$7 \mathrm{E}$ & 6,5 & 6,3 & -- & 9,1 & 7,3 \\
$8 \mathrm{E}$ & 8,1 & 4,6 & 6,1 & 10,7 & 7,4 \\
$9 \mathrm{E}$ & 10,6 & 4,9 & 4,6 & 5,7 & 6,4 \\
$10 \mathrm{E}$ & 9,9 & -- & 11,9 & 9,6 & 10,4 \\
$11 \mathrm{E}$ & 5,6 & 6,0 & 7,1 & 10,4 & 7,3 \\
$12 \mathrm{E}$ & 6,8 & 4,3 & 7,2 & 9,4 & 6,9 \\
\hline
\end{tabular}

$\mathrm{E}=$ EPAMIG. $---=$ clones da cultivar Folha de Figo sem produção.

As oscilações de produção verificadas entre anos para um mesmo clone podem ser atribuídas à ocorrência de desavinho (aborto das bagas e má formação do cacho), fato comum para esta cultivar. Variações de produção entre clones foram também constatada por Regina \& Audeguin (2005) em estudos de seleção clonal, que observaram diferenças significativas de comportamento produtivo entre clones de videira cv. Syrah (Vitis vinifera), na região de Caldas. 
VILLA, L. et al. Prospecção clonal e ocorrência de viroses...

\section{Outros vinhedos do município de Caldas}

A prospecção realizada em 17 vinhedos particulares com plantas cultivadas em pé-franco e com idade superior a 20 anos, levou à identificação inicial de 137 plantas que apresentavam melhor aspecto vegetativo, produtivo e sanitário, além de identidade varietal indiscutivel.

Por ocasião da colheita, a pesagem da produção levou a uma oscilação da produção situada entre 1,150 e 15,410 kg planta ${ }^{-1}$ e índice de fertilidade entre 0,34 e 3,19 cachos/ramo.
Comprova-se, assim, a grande variação do potencial produtivo das plantas existentes no interior dos vinhedos, demonstrando que, mesmo em vinhedos de baixa produtividade, podem-se encontrar plantas com produção elevada, evidenciando a importância da seleção clonal.

Das 137 plantas inicialmente selecionadas, 13 apresentavam produção superior a $5,0 \mathrm{~kg}$ planta 1 (Tabela 2). As variações nos teores de açúcar e acidez total variaram entre $8,0-10^{\circ}$ Brix e 3,8-6,5 $\mathrm{cmol}_{\mathrm{c}} \mathrm{dm}^{-3}$, respectivamente (Tabela 2 ).

TABELA 2 - Produção, ${ }^{\circ}$ Brix e acidez total de clones da cultivar Folha de Figo (Vitis labrusca L.). selecionados nos viticultores. EPAMIG, Caldas.

\begin{tabular}{cccc}
\hline Clone & $\begin{array}{c}\text { Produção } \\
\left(\mathrm{kg} \mathrm{planta}^{-1}\right)\end{array}$ & ${ }^{\circ}$ Brix & $\begin{array}{c}\text { Acidez }^{-3} \\
\left(\mathrm{cmol}_{\mathrm{c}} \mathrm{dm}^{-3}\right)\end{array}$ \\
\hline 1P & 9,75 & 9,0 & 6,0 \\
2P & 11,8 & 9,0 & 3,8 \\
3P & 11,1 & 9,0 & 4,2 \\
4P & 9,7 & 9,0 & 3,9 \\
5P & 9,6 & 9,0 & 5,6 \\
6P & 9,4 & 10,0 & 5,4 \\
7P & 14,6 & 8,0 & 6,5 \\
8P & 10,4 & 10,0 & 6,4 \\
9P & 9,3 & 10,0 & 4,7 \\
10P & 9,3 & 11,0 & 5,3 \\
11P & 10,4 & 10,0 & 5,5 \\
12P & 15,4 & 10,0 & 5,4 \\
13P & 9,4 & 9,0 & 5,8 \\
\hline
\end{tabular}

$\mathrm{P}=$ Produtor

Entretanto, as variáveis ${ }^{\circ}$ Brix e acidez total não devem ser consideradas com muito rigor, pois a data de colheita foi determinada pelos viticultores empregando-se processos empíricos e não em função do estado de maturação da uva (curva de acúmulo de açúcares), o que poderia informar a real capacidade das diferentes plantas em acumular açúcares e ácidos orgânicos. Por outro lado, há que se considerar também que os altos índices pluviométricos verificados durante o período de maturação desta safra influenciaram negativamente nos teores médios de açúcar observados.

Após avaliação do índice de fertilidade das gemas, uma vez que as plantas selecionadas apresentavam grande variação na carga de gemas, afetando a análise da produção, estabeleceram-se, de forma arbitrária, os limites mínimos de produção de 5,0 kg planta ${ }^{-1}$ e/ou índice de fertilidade de 1,0, sendo então possível redefinir o quadro de plantas selecionadas em 19 clones.

Por ocasião da poda de inverno, foram retiradas estacas de cada uma das 19 plantas préselecionadas para multiplicação em vasos sob cultivo protegido. Em função da qualidade das estacas e da idade avançada das plantas, o enraizamento só foi possível em 19 clones, somados os selecionados na EPAMIG e nos viticultores (Tabela 3 ) que foram mantidos em vasos para a etapa posterior da seleção.

O clone de número 3 , com produção e fertilidade de gemas inferiores foi mantido no stand como testemunha local.

\section{Indexação viral}

Pelo teste de ELISA, observou-se a presença dos vírus do enrolamento da folha da videira (GLRaV-3) nos clones 3, 4 e 14 (15,79\% das amostras). O vírus da canelura do tronco da videira (GVA) também foi detectado nos clones 1, 2, 4, 5, 9 e 11 (31,58\% infectados). Não foram detectados os vírus GVB, GLRaV-1, GFRV e GFLV em nenhum dos clones (Tabela 4). 
VILLA, L. et al. Prospecção clonal e ocorrência de viroses...

TABELA 3 - Produção, teor de açúcares ('Brix), acidez total e índice de fertilidade de clones selecionados da cultivar Folha de Figo (Vitis labrusca L.) na EPAMIG, Caldas, MG.

\begin{tabular}{ccccc}
\hline Clone & $\begin{array}{c}\text { Produção } \\
\left(\text { kg planta }^{-1}\right)\end{array}$ & ${ }^{\circ}$ Brix & $\begin{array}{c}\text { Acidez } \\
\left(\mathrm{cmol}_{\mathrm{c}} \mathrm{dm}^{-3}\right)\end{array}$ & $\begin{array}{c}\text { Índice de } \\
\text { fertilidade }^{1}\end{array}$ \\
\hline 01 & 9,30 & 11,0 & 5,30 & 1,37 \\
02 & 7,40 & 11,0 & 5,60 & 0,71 \\
$03^{*}$ & 1,50 & 9,0 & 3,90 & 2,77 \\
04 & 6,48 & 12,5 & 3,92 & 2,76 \\
05 & 7,29 & 11,5 & 4,51 & 1,87 \\
06 & 14,60 & 8,0 & 6,60 & 2,29 \\
07 & 7,88 & 10,5 & 3,43 & 1,63 \\
08 & 4,80 & 14,0 & 4,70 & 2,29 \\
09 & 7,68 & 9,5 & 4,31 & 0,86 \\
10 & 8,00 & 9,0 & 5,30 & 1,49 \\
11 & 9,65 & 9,0 & 5,70 & 1,61 \\
12 & 11,15 & 9,0 & 4,20 & 1,02 \\
13 & 8,35 & 9,0 & 4,70 & 1,64 \\
14 & 7,41 & 13,0 & 3,82 & 1,00 \\
16 & 7,40 & 10,0 & 5,20 & 3,19 \\
17 & 11,80 & 9,0 & 3,80 & 1,38 \\
19 & 10,40 & 10,0 & 6,40 & 1,08 \\
\hline 3 & 15,40 & 10,5 & 5,40 & 2,25 \\
\hline
\end{tabular}

${ }^{*}$ Clone 3 = testemunha; ${ }^{1}=$ Índice de fertilidade de gemas/planta = número de cachos/ramos

TABELA 4 - Ocorrência de quatro diferentes viroses em 19 amostras de folhas da cultivar Folha de Figo (Vitis labrusca L.). EPAMIG, Caldas, MG.

\begin{tabular}{ccccc}
\hline $\begin{array}{c}\text { Clones de } \\
\text { 'Folha de figo' }\end{array}$ & GVA & GVB & GLRaV-1 & GLRaV-3 \\
\hline 1 & + & - & - & - \\
2 & + & - & - & - \\
3 & - & - & - & + \\
4 & + & - & - & + \\
5 & + & - & - & - \\
6 & - & - & - & - \\
7 & - & - & - & - \\
8 & - & - & - & - \\
9 & + & - & - & - \\
10 & - & - & - & - \\
11 & + & - & - & - \\
12 & - & - & - & - \\
13 & - & - & - & - \\
14 & - & - & - & - \\
15 & - & - & - & - \\
16 & - & - & - & - \\
18 & - & - & - & \\
19 & - & - & - & - \\
\hline
\end{tabular}

- = ausência de vírus (controle negativo); + = presença de vírus (controle positivo). 
VILLA, L. et al. Prospecção clonal e ocorrência de viroses...

Para Kuhn \& Fajardo (2002), as videiras americanas e híbridas, que predominam em área cultivada no Brasil, não mostram os sintomas característicos das viroses, quando infectados pelos vírus, o que torna impossível a distinção entre plantas sadias e doentes pela simples observação virusal. Por isso faz-se necessário o uso de técnicas sorológicas de diagnoses viróticas, como o teste de ELISA.

Os mesmos vírus avaliados neste estudo já foram descritas no Brasil para vinhedos de cultivares americanas no Rio Grande do Sul (Kuhn \& Nickel, 1998) e São Paulo (Kuniyuki et al., 2003). $\mathrm{O}$ vírus que causa o enrolamento da folha da videira (GLRaV) já chegou a atingir $78 \%$ a $98 \%$ das produtoras viníferas (Fajardo et al., 2007).

Boscia et al. (1992) determinaram a incidência de GVA em 1.100 videiras na Itália, provenientes de coleções de cultivares, mantidas em campo e com diferentes origens geográficas. O GVA foi detectado em $20 \%$ das amostras, com grande variação de incidência entre as origens geográficas. No Brasil, Kuhn et al. (2002) analisaram a infecção por GVA em amostras de videiras americanas, provenientes de municípios da principal região vitícola do Rio Grande do Sul, e encontraram níveis de infecção de 6,1 a 8,6\%.

Pode-se ressaltar que os seis clones positivos para o GVA foram identificados tanto no vinhedo da EPAMIG quanto nos vinhedos particulares, ou seja, tratavam-se ao mesmo tempo de plantas enxertadas ou pé-franco, mostrando que a disseminação destas viroses pode ter sido feita tanto por enxertia/estaquia e tratos culturais como poda, quanto pela possível disseminação por vetores. Há de se considerar ainda que todas as plantas positivas apresentaram produções médias superiores a $5,0 \mathrm{~kg}$ planta $^{-1}\left(13,29 \mathrm{t} \mathrm{ha}^{-1}\right)$, comprovando que as variedades da espécie Vitis labrusca podem tolerar com certas viroses sem prejuízo à produtividade. As diferenças de produtividade e/ou fertilidade das gemas observadas durante a prospecção inicial podem ser devidas à condição agronômica em que a planta estava inserida e não necessariamente às variações genéticas para produtividade (Tabela 5).

TABELA 5 - Produção média (kg planta ${ }^{-1}$ ) dos clones com viroses da cultivar Folha de Figo. EPAMIG, Caldas.

\begin{tabular}{ccc}
\hline Clone & Vírus & Produção $\left(\mathrm{kg} \mathrm{planta}^{-1}\right)$ \\
\hline 01 & GVA & 9,30 \\
02 & GVA & 7,40 \\
$03^{*}$ & GLRaV-3 & 1,50 \\
04 & GVA e GLRaV-3 & 6,48 \\
05 & GVA & 7,29 \\
09 & GVA & 7,68 \\
11 & GVA & 9,65 \\
14 & GLRaV-3 & 7,41 \\
\hline
\end{tabular}

${ }^{*}$ Clone 03 = testemunha

Em estudos futuros, se os clones que estavam infectados pelo vírus associado ao enrolamento da folha da videira (GLRaV-3) e canelura do tronco da videira (GVA) forem considerados plantas superiores, em termos agronômicos e genéticos, terão que passar posteriormente, por três fases distintas para eliminação destes vírus, sendo elas: a) indexação, b) termoterapia e c) cultura de meristemas (Kuhn, 1999) e posterior certificação, antes da sua distribuição aos produtores.

Desta forma, pode-se considerar que o estado sanitário dos clones selecionados no Sul de Minas Gerais é relativamente bom, e que as baixas produtividades diagnosticadas, a princípio, não são apenas de ordem sanitária, podendo ser atribuídas a outros fatores, tais como nutrição mineral, genético e manejo, conforme já detectado por Regina et al. (1998).

Os resultados obtidos neste trabalho fornecem muitos subsídios para estudos futuros, para a utilização de 'Folha de Figo' na indústria vinícola da região de Caldas, visto que, na maioria dos trabalhos encontrados com seleção clonal e sanitária em videira, foram utilizadas cultivares de Vitis vinifera, predominando as uvas destinadas à vinicultura e preferidos pelos viticultores da região.

\section{CONCLUSÕES}

Variação de produção ( $\mathrm{kg}$ planta $\left.^{-1}\right)$ é verificada no interior dos vinhedos na região de Caldas, durante a etapa de prospecção.

Detectaram-se os vírus do enrolamento da folha e da canelura do tronco em alguns clones de Folha de Figo selecionados nos vinhedos de Caldas, MG, os quais não afetaram a produtividade destas videiras.

\section{AGRADECIMENTOS}

Os autores agradecem à Fundação de Amparo à Pesquisa do Estado de Minas Gerais (FAPEMIG). 
VILLA, L. et al. Prospecção clonal e ocorrência de viroses...

\section{REFERÊNCIAS}

1. AMORIM, L.; KUNIYUKI, H. Doenças da videira. In: KIMATI, H. et al. (Ed.) Manual de Fitopatologia, v.2: Doenças de plantas cultivadas. 1. ed. São Paulo. Agronômica Ceres. 1997. p. 736-757.

2. BOSCIA, D. et al. Production, characterization and use of monoclonal antibodies to Grapevine virus A. Archives of Virology, v. 127, n. 1-4, p.185-194, 1992.

3. CLARK, M. F.; ADAMS, A. N. Characteristics of the microplate method of enzyme-linked immunosorbent assay for detection of plant viruses. Journal of General Virology, v. 34, n. 3, p. 475-483, 1977.

4. FAJARDO, T. V. M. et al. Caracterização parcial de um isolado do Grapevine fanleaf virus. Fitopatologia Brasileira, v. 25 , n. 3 , p. $505-511,2000$

5. FAJARDO, T. V. M. et al. Variability of the coat protein gene of Grapevine leafroll-associated virus 3 in Brazil. Fitopatologia Brasileira, v. 32, n. 4, p. 335-340, 2007.

6. GONÇALVES, C. A. A. Comportamento da cultivar Folha de Figo (Vitis labrusca L.) sobre diferentes portaenxertos de videira. 1996. 45 f. Dissertação (Mestrado em Fitotecnia) - Universidade Federal de Lavras, Lavras, 1996.

7. KUHN, G. B. Vírus do entumescimento dos ramos associado à morte de plantas de cultivares Vitis vinifera. Bento Gonçalves: EMBRAPA-CNPUV, 1999. 4 p. (Comunicado Técnico, 32)

8. KUHN, G. B. et al. O cultivo da videira: informações básicas. 2. ed. Bento Gonçalves: EMBRAPA/CNPUV, 1996. 60 p. (Circular Técnica, 10).

9. KUHN, G. B.; FAJARDO, T. V. M. Viroses da videira no Brasil. In: EMPRESA BRASILEIRA DE PESQUISA AGROPECUÁRIA (EMBRAPA). Curso de capacitação técnica em viticultura: módulo 3. Bento Gonçalves: EMBRAPA-CNPUV, 2002. p.1-6.

10. KUHN, G. B.; NICKEL, O. Viroses e sua importância na viticultura brasileira. Informe Agropecuário, v. 19, n. 194, p. 85-91, 1998

11. KUNIYUKI, H.; GASPAR, J. O.; REZENDE, J. A. M. Ocorrência do Grapevine leafroll-associated virus 6 em vinhedos do Brasil. Summa Phytopathologica, v. 29, n. 3, p. 288-289, 2003.

12. KUNIYUKI, H. et al. Identificação sorológica do vírus do mosaico das nervuras da videira no Brasil. Fitopatologia Brasileira, v. 27, n. 6, p. 635-638, 2002

13. MARTELI, G.P. Grapevine virology lighlights. In: MEETING OF THE INTERNATIONAL COUNCIL FOR THE STUDY OF VIRUS AND VIRUS-LIKE DISEASES OF THE GRAPEVINE (ICGV), 15., 2006, Stellenbosch. Extended Abstracts... Stellenbosch: South African Society for Enology and Viticulture, 2006. p. 3-18

14. REGINA, M. A.; AUDEGUIN, L. Avaliação ecofisiológica de clones de videira cv. Syrah. Ciência e Agrotecnologia, v. 29 , n. 4, p. $875-879,2005$

15. REGINA, M. A. et al. Levantamento nutricional e diagnóstico agronômico dos vinhedos de Caldas. Revista Brasileira de Fruticultura, v. 20, n. 1, p. 15-20, 1998

16. SOUZA, C. M. et al. Indicação de cultivares de videira para o Sul de Minas Gerais. In: SIMPÓSIO MINEIRO DE VITICULTURA E ENOLOGIA, 1., 2002, Andradas. Anais... Andradas: Atualizando Conceitos, 2002. p. 277-286.

Recebido em: 13/03/2009 Aceito em: 28/10/2009 
